\title{
Evolution and impact of cellulose architecture during enzymatic hydrolysis by fungal cellulases
}

\author{
Marie Chauve $^{1,2}$, Loic Barre ${ }^{1}$, Sandra Tapin-Lingua ${ }^{3}$, Denilson da Silva Perez ${ }^{3}$, \\ Dominique Decottignies $^{2}$, Serge Perez ${ }^{4,5}$, Nicolas Lopes Ferreira ${ }^{{ }^{*}}$ \\ ${ }^{1}$ IFP Energies Nouvelles, Rueil-Malmaison, France \\ ${ }^{2}$ IFP Energies Nouvelles, Rond-Point de l'Échangeur de Solaize, Solaize, France \\ ${ }^{3}$ FCBA, Pôle NMA, Domaine Universitaire, Grenoble, France \\ ${ }^{4}$ ESRF, Rue Jules Horowitz, Grenoble, France \\ ${ }^{5}$ Centre de Recherches sur les Macromolécules Végétales, CNRS; Affiliated with Université de Grenoble, Grenoble, France \\ Email: spsergeperez@gmail.com, ${ }^{*}$ nicolas.lopes-ferreira@ifpen.fr
}

Received 30 June 2013; revised 15 November 2013; accepted 2 December 2013

Copyright (C) 2013 Marie Chauve et al. This is an open access article distributed under the Creative Commons Attribution License, which permits unrestricted use, distribution, and reproduction in any medium, provided the original work is properly cited.

\begin{abstract}
The enzymatic hydrolysis of cellulose is still considered as a main limiting step of the biological production of biofuels from ligno-cellulosic biomass. Glycoside hydrolases from Trichoderma reesei are currently used to produce fermentable glucose units from degradation of cellulose packed in a complex assembly of cellulose microfibrils. The present work describes the structural evolution of two prototypical samples of cellulose (a micro-crystalline cellulose and a bleached sulfite pulp) over 5 length scale orders of magnitude. The results were obtained through wide angle, small angle and ultra-small angles synchrotron $X$-ray scattering, completed by Small Angle Neutron Scattering and particle size analyzers. These structural evolutions were followed as a function of enzymatic conversion. The results show that whereas there is no change at the nanometer scale, drastic changes occur at micron. The observed decrease of the size of the cellulose particles is accompanied by a smoothing of the crystalline surfaces that can be explained by a two-step mechanism of the enzymatic hydrolysis.
\end{abstract}

Keywords: Cellulose; Cellulase; Trichoderma reesei; Synchrotron X-Ray Scattering; Neutron Scattering; Particle Size

\section{INTRODUCTION}

Whereas the biological production of ethanol from biomass is currently investigated as an alternative to liquid fossil fuels exclusively used in transport [1], the re-

"Corresponding author. quirement for high-yield, low cost efficient deconstruction of the plant material is critically needed. Plant biomass exhibits extreme recalcitrance, i.e. resistance to breaking down the complex combination of material properties and structural organisation into constituent units. This is a major issue in the generation of bioethanol from cellulosic substrates sugars using glycoside hydrolases produced by industrial strains of Trichoderma reesei [2]. In the process of bioethanol production, enzymatic hydrolysis is still considered as one of the main limiting step in which the large amount of enzymes required. The enzymatic breakdown and degradation of cellulose require a complex of enzymes working together. The synergetic action of at least three types of enzymes is required for efficient digestion of crystalline cellulose into glucose [3,4]. These are: 1) endoglucanases (EG; EC 3.2.1.4) which cleave the chains randomly, 2) cellobiohydrolases (CBH; EC 3.2.1.91) which recurrently cleave cellobiose from the chain end of cellulose and 3) $\beta$-glucosidases (EC 3.2.1.21) which hydrolyse cellobiose. Other complementarities are found among these enzymes, as exemplified by the synergistic action of two cellobiohydrolases, namely Cel6A and Cel7B from organisms such as Trichoderma reesei and Humicola insolens $[5,6]$. The Carbohydrate Binding Module (CBM) of cellulases also plays a fundamental role in the hydrolysis of the solid substrate. Even if the exact function of this CBM is still controversial [7], the specific planar binding surface of the CBM allows the enzyme to adhere to the hydrophobic face of the sugar molecules thus enhancing the activity of the linked catalytic module toward crystalline cellulose [8]. After a first step of adsorption onto the microfibrils, the cellulolytic enzymes are then able to 
cleave cellulose chains leading to substrate morphological changes. The reaction rate decreases dramatically with the extent of conversion and this slowdown could be explained by enzyme related factors such as enzyme inactivation $[8,9]$ and product inhibition $[10,11]$ or by changes in substrate reactivity [12-14].

The molecular level can be mainly described by the degree of polymerization, the nanostructure is characterized by the crystallinity or the porosity and finally, the microstructure can be associated to the fibre network [15-20]. Mansfield et al. [21] detailed the existing substrate factors limiting the hydrolysis at different structural levels. Several factors, such as crystallinity $[13,22$, 23 ] and degree of polymerization [24] have been proved to have an influence on the initial hydrolysis rate of cellulose. However, few studies have been devoted to the morphological changes occurring during the enzymatic hydrolysis. Several hypotheses are developed in the literature to explain the mechanisms of cellulose disruption such as swelling, pitting or decrystallization of the cellulosic complex [25].

The latest mechanistic studies suggest an erosive action of the cellulases during which exoglucanases such as Cel7A processively hydrolyze cellulose chains from the reducing end by removing successive cellobiose units, whereas endoglucanases Cel6A interacts with the surface of the microfibril with an allosteric coupling effect [26]. Wang et al. [27] have visualized by AFM the topographic changes caused by Cel6A, including the swelling of the crystalline microfibrils and its capacity to expose single microfibrils.

As for molecular changes, acid hydrolysis pre-treatment was shown to dramatically decrease the degree of polymerisation compared to enzymatic hydrolysis [28, 29]. Other studies $[30,31]$ pointed out a correlation between reduction of the degree of polymerization and the conversion rate, but this change seems to be weak compared to the conversion rate $[32,33]$ but enzymes could not penetrate the dense cellulose structure whereas acid could lead to a dramatic reduction of the degree of polymerization [21].

At the nanostructural level, one of the most studied parameters has been the alteration of the degree of crystallinity during enzymatic hydrolysis [34]. The role of crystallinity during enzymatic hydrolysis is still controversial and may not directly explain the slowdown of the reaction. Chen et al. [33] and Wang et al. [35] found only a slight increase of conversion whereas some authors did not find any increase of the crystallinity index $[14,36]$. Other techniques were recently used to characterize nanometer changes in cellulose structure such as smallangle X-ray scattering (SAXS) [36] or small-angle neutron scattering (SANS) [37] which are suitable for the interface characterization. Investigating the changes at low q reveals a slight increase in the surface area during enzymatic hydrolysis probably due to surface erosion or agglomerate breakup [37]. Evolution of the cellulose surface morphology was recently investigated by SANS [38] which has the advantage to be a non-destructive and more penetrating technique than SAXS. This was also investigated by scanning electron microscopy (SEM) and results showed a clear decrease in the length of cotton linters and a non-uniformity of particle size after several hours of enzymatic hydrolysis [29,35]. Using Fiber Quality Analyser Park et al. [39] showed a clear decrease in particle size and other authors [3,37] correlated the particles size decrease to the increase in surface area.

However, more surface area suggests an increase of the cellulose accessibility to the enzymatic attack, which should cause an increase in the hydrolysis rate but not a slowdown. Restarting hydrolysis with fresh enzyme is an adequate experiment to measure the losses of substrate reactivity [35,40-42]. It is still difficult to explain the decrease of the reaction rate vis a vis the evolution of morphological features of the substrate. The present work aims at characterizing the evolution of structure of cellulosic substrates along with their reactivity as a function of conversion. To do so, two different cellulosic substrates differing in their degree of polymerization were investigated; these are Avicel crystalline cellulose, and a bleached sulfite pulp (BSP) having a degree of polymerization more representative of substrates from lingocellulosic biomass. Partially hydrolysed substrates were prepared to investigate the structural and morphological changes occurring at different scales using various analytical methods such as viscosity measurement, WAXS, SAXS, SANS and particle size analyser. The changes of reactivity as a function of conversion were monitored by testing substrate reactivity with fresh enzymes and correlation between morphological and structural changes occurring during enzymatic hydrolysis of these cellulosic substrates were investigated.

\section{EXPERIMENTAL SECTION}

\subsection{Materials}

Two cellulosic substrates were used in this study: 1) a microcrystalline cellulose (AVICEL PH101), and 2) bleached sulphite pulp (BSP) form soft wood with a cellulose content of $96 \%$ produced by TEMBEC Tartas (France).

Cellobiose was purchased from Sigma-Aldrich (Sigma-Aldrich, Lyon, France). Glucose was obtained from Prolabo (Prolabo, Fontenay sous bois, France); cellotriose, cellotetraose, cellopentaose and cellohexaose were purchased from Seikagaku (Seikagaku, Japan). All buffer components and salts used were reagent grade and purchased from Sigma-Aldrich and GE Healthcare (GE 
Healthcare, Saclay, France). Purified water (18 M $\Omega$; Milli-Q Plus Water Purification System; Millipore, Bedford, MA, USA) was used to prepare all solutions. $\mathrm{D}_{2} \mathrm{O}$ was purchased from EURISTOP $\left(\mathrm{D}_{2} \mathrm{O} 100 \%\right.$; $\left.215 \mathrm{H}\right)$.

Enzymatic cocktails were obtained from a crude enzyme preparation produced by the hyper cellulolytic strain T. reesei CL847 [43]. The production followed the procedure previously described by Herpoel-Gimbert [44]. Commercial $\beta$-glucosidase preparation was purchased from Novozymes (SP188; Novo Nordisk A/S, Bagsvaerd, Denmark).

\subsection{Methods}

Partially hydrolysed substrate preparation. Cellulose at a concentration of $2 \% \mathrm{w} / \mathrm{v}$ was hydrolysed at enzyme loadings ranging from 1 to $10 \mathrm{mg} / \mathrm{g}$ cellulose for different times in a $2 \mathrm{~L}$ reactor $\left(50^{\circ} \mathrm{C}, \mathrm{pH} 4.8,50 \mathrm{mM}\right.$ citrate buffer) under mechanical stirring. Additionnal $\beta$-glucosidase from SP188 was added to avoid cellobiose accumulation. The remaining cellulose residues were recovered by centrifugation $\left(15^{\circ} \mathrm{C} / 13,000 \mathrm{~g} / 5 \mathrm{~min}\right)$. The solid residue was first washed at $\mathrm{pH} 10$ using $\mathrm{NaOH}(2 \mathrm{~N})$ and further with distilled water to remove all bound enzymes. The solid was freeze-dried to be recovered as a powder. For each substrate, a control substrate was prepared under the same conditions but without any enzyme.

Enzymatic hydrolysis. For initial kinetic tests, experiments were performed in $7 \mathrm{~mL}$ tubes $\left(50^{\circ} \mathrm{C}, \mathrm{pH} 4.8\right.$, $50 \mathrm{mM}$ of citrate buffer) under magnetic stirring (400 rpm; Variomag 15.40 Fisher Scientific, Illkirch, France). Cellulose at concentration of $1 \% \mathrm{w} / \mathrm{v}$ was submitted to the action of enzymes at concentrations ranging from 3 to $15 \mathrm{mg} / \mathrm{g}$ in a final volume of $1 \mathrm{~mL}$. Assays were carried out in duplicate for 5, 10, 20 and 30 minutes. Reactions were stopped by boiling in water bath $\left(95^{\circ} \mathrm{C}, 5 \mathrm{~min}\right)$ and then cooled on ice and filtered $(0.2 \mu \mathrm{m}$ nylon acrodisc 13). Glucose and cellobiose concentrations were determined by high performance liquid chromatography using a method previously described $[45,46]$.

For global kinetic tests, duplicates were performed in $100 \mathrm{~mL}$ flacon $\left(50^{\circ} \mathrm{C}, \mathrm{pH} 4.8,50 \mathrm{mM}\right.$ citrate buffer) using magnetic stirring (1200 rpm). Cellulose at concentration of $1 \% \mathrm{w} / \mathrm{v}$ was hydrolysed by the enzymes (at 20 $\mathrm{mg} / \mathrm{g}$ of cellulose) in a final volume of $70 \mathrm{~mL}$. One $\mathrm{mL}$ samples were taken at 1, 2, 4, 6, 24, 48, 72, $144 \mathrm{~h}$, then boiled and centrifuged. Sugar formed in the supernatant was measured using a glucose analyzer YSI.

Measurement of the degree of polymerization. The degree of polymerisation (DP) of all cellulosic samples was determined by measuring the intrinsic viscosity of the cellulose after dissolution in cupri-ethylene-diamine (CED) following ISO 5351-1 and Tappi T230 om-94 norms. Measurements were performed on an automatic viscosimeter RHEOTEK RPV-1 following the norm ISO 5351-1. DPs were evaluated following the equation established by Evans [47].

$$
D P^{0.9}=1.65 \cdot[\eta]
$$

where $\eta$ is the viscosity in $\mathrm{mL} / \mathrm{g}$.

Wide Angle X-ray Scattering (WAXS) measurement. The samples were prepared by pressing cellulose powder by hand into PVC rings having diameter of 2 $\mathrm{mm}$ and thickness of $1 \mathrm{~mm}$. An X-ray generator (Philips PW 3830) working with a voltage of $30 \mathrm{kV}$ and a $\mathrm{CuK} \alpha$ radiation $(\lambda=0.15418 \mathrm{~nm})$ was used. The scattered intensity was recorded on an image plate detector (Fujifilm) and measured using a bio-imaging analyser (Fujifilm BAS 1800 II). Each sample was exposed for 30 minutes at room temperature under vacuum. The instrumental broadening was determined by measuring a sample of calcite.

Scattering experiments. A series of scattering experiments investigated the degree of the organisation of cellulose when it is in aqueous environment. Suspensions were prepared by immersing cellulose powder in the solvent for at least one night to achieve the swelling of cellulose.

Small and Ultra Small X-ray Scattering measurements: To probe the relevant length scales of cellulose modifications, a series of scattering experiments was performed. The combination of Ultra Small Angle X-ray Scattering (USAXS), Small Angle X-ray Scattering (SAXS) and Wide Angle X-ray Scattering (WAXS) allows coverage of a broad range of $\mathrm{q}$ corresponding to length scales going from microns down to angstrom. These experiments were performed at the ID02 beam line of the European Synchrotron Radiation Facility in Grenoble, France. Suspensions of water-swollen cellulose were centrifuged in order to recover the slurry (10 $20 \mathrm{wt} \%$ of particles in water). The slurries were loaded in cells of $0.125 \mathrm{~cm}$ optical path closed by two mica windows. The same preparation was used for every experimental setup (USAXS, SAXS and WAXS). There was no attempt to accurately measure the cellulose concentration in the X-ray beam for these experiments.

Combined SAXS/WAXS: SAXS and WAXS measurements were performed simultaneously. The SAXS detector is a Frelon 4M CCD camera with a $2048 \times 2048$ pixels chip of a total $10 \times 10 \mathrm{~cm}^{2}$ surface. Two sampleto-detector distances were used: $1 \mathrm{~m}$ and $10 \mathrm{~m}$ along with a $0.1 \mathrm{~nm}$ wavelength $\mathrm{X}$-ray beam, giving values of the scattering vector q ranging from $8.8 \times 10^{-2} \mathrm{~nm}^{-1}$ to $4.8 \mathrm{~nm}^{-1}$. The WAXS detector is an Aviex PCCD-4284 camera. This detector is mounted in an erected configuration without requiring any special geometrical or distortion corrections. The WAXS q-range lies from 3.4 
$\mathrm{nm}^{-1}$ to $4 \times 101 \mathrm{~nm}^{-1}$.

During the acquisition, standard corrections are made for X-ray beam transmission and monitor, detector efficiency and distortion and applied to the recorded CCD image. A measurement of pure water is done to calibrate the instrument. Para-bromo-benzoic acid was used to calibrate WAXS angles. SAXS 2-D images are then azimuthally regrouped after applying a mask to remove faulty regions of the image (essentially due to the beamstop). A final subtraction of the mica windows and a normalization by the sample thickness gives the scattering cross section $\mathrm{I}(q)$ in absolute units $\left(\mathrm{cm}^{-1}\right)$.

Ultra Small Angle X-ray Scattering. A Bonse-Hart camera [48] equipped with an avalanche photodiode detector was used on the ID02 beam line to measure the Ultra Small Angle X-ray Scattering corresponding to $q$ values ranging from $5.5 \times 10^{-4} \mathrm{~nm}^{-1}$ to $2 \times 10^{-1} \mathrm{~nm}^{-1}$. The scatttering of the mica windows was subtracted from the sample signal and the resulting intensity was normalized by sample thickness to obtain the scattering cross section in absolute units $\left(\mathrm{cm}^{-1}\right)$.

Small Angle Neutron Scattering (SANS) measurements. SANS measurements were performed at the Laboratoire Léon Brillouin (LLB, Saclay, France) on the PAXE instrument. The PAXE detector is a XY multidetector filled by $\mathrm{BF}_{3}$. Two different configurations (wavelength $\lambda_{0}=1.7 \mathrm{~nm}$, Sample-to-Detector distance $=$ $5 \mathrm{~m}$; and wavelength $\lambda_{0}=0.6 \mathrm{~nm}$, Sample-to-Detector distance $=2 \mathrm{~m}$ ) were used to cover q values ranging from $2.8 \times 10^{-2} \mathrm{~nm}^{-1}$ to $1.8 \mathrm{~nm}^{-1}$. Data processing was performed using the standard PAXE procedures (software available free of charge at http://didier.lairez.fr/) [49]. For high q values, absolute intensity was obtained by measuring the incident flux. Scattered intensities were normalized by the thickness of the sample and the transmission. Finally, the signal of an empty cell and the incoherent background, mainly coming from the hydrogen atoms of the cellulose and the physiosorbed $\mathrm{H}_{2} \mathrm{O}$, were subtracted. The incoherent contribution was calculated by estimating the total amount of hydrogen of the cellulose sample. Data obtained for low q values were normalised with high $q$ values data (software available free of charge at http://didier.lairez.fr/). The cellulose suspension was then introduced in $2 \mathrm{~mm}$ Hellma quartz cells for the analysis and the excess of solvent was removed by centrifugation to avoid any particle sedimentation. The operation has been repeated until the cell is full. The dry matter content was measured after the SANS analysis to determine exactly the volume fraction of cellulose in the cell. Solvents were also analysed in 2 mm Hellma cells.

Data analysis: WAXS Analysis. The crystallinity index was calculated using the classical peak intensity method:

$$
C r I=\frac{I_{C r}-I_{a m}}{I_{C r}} \cdot 100
$$

where $I_{C r}$ is the intensity at $2 \theta=22^{\circ}$, and $I_{a m}$ is the intensity at $2 \theta=18^{\circ}$. The $I_{C r}$ peak corresponds to the crystalline fraction whereas $I_{a m}$ corresponds to the amorphous fraction.

SANS and SAXS Analysis. For mono-disperse, homogeneous, spherical particles suspended in a solvent, the scattered intensity can be written as:

$$
I(q)=\left(\rho_{\text {part. }}-\rho_{\text {solv. }}\right)^{2} N_{p} V_{p}^{2} F^{2}(q) S(q)
$$

where $N_{p}$ is the average number density of particles; $V_{p}$ is the average volume of one particle and $N_{p} V_{p}$ is the volume fraction $\phi$ of particles; $F^{2}(q)$ is the form factor giving information relative to the size, shape and internal structure of the particles; and $S(q)$ is the structure factor describing the interaction between particles.

Neutron contrast variation experiments measure the scattering length densities (SLD) of particles. For that, different $\mathrm{H} / \mathrm{D}$ solvent mixtures are used and the resultant solvent SLD is the volume fraction weighted sum of $\rho$ of each constituent. For any $q$ value, the expression (3) can be expressed as follows:

$$
\left(\frac{I(q)}{\phi}\right)^{1 / 2} \propto \rho_{\text {part }}-\rho_{\text {solv. }} .
$$

A plot of the left hand side of (3bis) as a function of $\rho_{\text {solv }}$. yields an estimation of $\rho_{\text {part }}$.

The $q$ domain measured by X-ray scattering is from 0.001 to $40 \mathrm{~nm}^{-1}$; it determines the length scale $(\sim 1 / q)$ of detectable features between 0.2 and $1000 \mathrm{~nm}$. This length scale is one or two orders of magnitude lower than the cellulose particle size as seen by microscopic methods. Consequently, the correct description of the form and structure factor is not possible in this $q$ range. By contrast the water/microfibril and/or the water/particle interface can be characterized giving insight into the result of the mechanism of actions of enzymes. In the $q$ domain where $q^{-1}$ is much smaller than the particle size $R_{g}$ and if the SLD vary sharply from particle to solvent, the intensity displays a q power law.

$$
I(q)=A\left(D_{s}\right) q^{-\alpha}, \quad q \gg R_{g}^{-1}
$$

where $\alpha$ is related to the surface fractal dimension $D_{s}$ by $\alpha=6-D_{s}$. If the particle/solvent interface is smooth $\left(D_{s}\right.$ $=2$ ), this equation can be simplified to give the Porod law:

$$
I(q)=A q^{-4}=2 \pi \Delta \rho^{2} \frac{S}{V} q^{-4}, \quad q \gg R_{g}^{-1}
$$

where $S$ is the developed surface in the volume $V$ and $S / V$ is the so called surface to volume ratio. For a suspension 
of particles at volume fraction $\phi$, the $S / V$ of the solution is related to the average surface to volume ratio of one particle $s / v$ by :

$$
\frac{S}{V}=\Phi \frac{s}{v}
$$

Particles sizes. Two different analytical methods were used to determine the sizes of the particles. The first method used the MorFi analyser (TechPap, France) which is able to analyse the size of particles ranging from $15 \mu \mathrm{m}$ to several millimeters.

An amount of $0.3 \mathrm{~g}$ of dry cellulose was suspended in water. The suspension passing throughout and in the vicinity of 3000 fibers per a couple of minutes were detected with a high resolution CCD (CCD: Charge-coupled device). Data were directly analysed yielding information about the size and the shape of particles such as length, width and circularity.

Particle size distribution was also determined using a Flow Particles Image Analyser (Sysmex FPIA3000, Malvern) which makes size and shape analysis of particles in suspension having size ranging from 1 to $300 \mu \mathrm{m}$. A sample is taken from a dilute suspension of particles which travel through a flow cell. Pictures of particles are imaged by a CCD. Random orientation is avoided and the largest area is presented to the camera. Pictures of 10,000 particles were taken, and length and width were determined for each particle. The arithmetic average length and width is computed for each substrate

\section{RESULTS}

\subsection{Preparation of Partially Hydrolysed Substrate}

Two cellulosic substrates having either a low- or high degree of polymerisation (DP) were prepared respectively from Avicel PH-101 (series I) and a cellulosic pulp named BSP (series II) respectively. The hydrolysis was interrupted at $10 \%, 30 \%$ and $70 \%$ of glucan conversion. For both substrates, a control was prepared without the enzymatic step to evaluate the influence of post-treatment. Hydrolysis of Avicel is accompanied by the accumulation of irreversibly adsorbed enzyme even after mild or extensive washing procedure as previously reported $[50,51]$. Several washing procedures have already been described in the literature and extensive alkaline wash was ascribed as being the most efficient [52]. Nevertheless, the use of harsh conditions such as high thermal denaturation under acidic conditions followed by an organic solvent washing, can dramatically alter the cellulose surface. To ensure the maximum removal of residual cellulase without affecting the surface properties, several mild alkaline wash steps, using a $2 \mathrm{M} \mathrm{NaOH}$ buffer and a thermal denaturation at $45^{\circ} \mathrm{C}$, were carried out. This was performed until no more protein was detectable by SDSPAGE analyses of washed buffers (data not shown). Using freeze-drying, the solid residue recovered is higher than $98 \%$ and the main features of the partially hydrolysed substrates are detailed in Table 1.

\subsection{Molecular Structure}

The molecular structure of cellulose was investigated using viscosity measurement. The average DP was determined both for the control and the partially hydrolysed substrates (Table 1). No significant change was observed for both low- and high-DP substrates indicating that the global molecular structure of cellulose remains constant during the saccharification. This result is in total agreement with those reported in the literature showing that enzymes are unable to penetrate microcrystalline

Table 1. Properties of prepared cellulosic substrates.

\begin{tabular}{|c|c|c|c|c|c|c|c|c|}
\hline Substrate & $\begin{array}{c}\text { Con. } \\
\text { Rate } \\
\%\end{array}$ & $\begin{array}{l}\text { Mean } \\
\text { DP }\end{array}$ & $\begin{array}{c}C r I \\
\%\end{array}$ & $\begin{array}{c}r_{1} \\
\mathrm{~nm}\end{array}$ & $\begin{array}{c}r_{2} \\
\mu \mathrm{m}\end{array}$ & $\begin{array}{c}\text { Fines } \\
\text { Part. } \\
\%\end{array}$ & $\begin{array}{l}\text { Length } \\
\mu \mathrm{m}\end{array}$ & $\begin{array}{c}\text { Width } \\
\mu \mathrm{m}\end{array}$ \\
\hline \multicolumn{9}{|c|}{ Serie I: Avicel } \\
\hline Control & 0.0 & 347 (17) & 64 & 3.4 & 1.2 & 98.5 & 11.6 & 7.2 \\
\hline A 10 & 10.0 & $359(18)$ & - & 3.4 & 0.8 & 96.9 & 10.7 & 5.4 \\
\hline $\mathrm{A} 30$ & 27.2 & $382(19)$ & 64 & 3.6 & 0.8 & 98.1 & 10.4 & 4.9 \\
\hline A70 & 76.3 & $369(18)$ & 63 & 3.0 & 0.3 & 99.3 & 11.0 & 3.9 \\
\hline \multicolumn{9}{|c|}{ Serie II: BSP } \\
\hline Control & 0 & $1916(96)$ & 56 & 3.8 & 1.2 & 59.3 & - & - \\
\hline BSP10 & 20.1 & $1884(94)$ & - & 6.1 & 1.4 & 62.5 & - & - \\
\hline BSP30 & 32.0 & $1869(93)$ & 62 & 5.2 & 1.0 & - & - & - \\
\hline BSP70 & 71.1 & $2108(105)$ & 60 & 4.0 & 0.5 & 92.0 & - & - \\
\hline
\end{tabular}


celluloses having a low DP [53-55] and act at the surfaces of the microfibrils $[51,56,57]$. Cellulases bind to the hydrophobic faces of crystalline cellulose and hydrolyze, progressively from the reducing end or randomly, the most exposed polysaccharide chains are located at the surface of the microfibrils. Our results demonstrate that irrespective of their degree of polymerization, cellulose crystals undergo an erosive action of enzymes, which results in a constant average degree of polymerization. This is contrary to what is observed in the case of amorphous substrates such as phosphoric acid swollen cellulose [57].

\subsection{Crystallinity}

Crystallinity is one of the several parameter used to characterize the ordered structure of cellulose. The determination of the crystallinity index is highly dependent on the characterisation method [39]. It has been recognized that the actual values of the crystallinity differ according to the measurement principles and analysis techniques used, and that the highest crystallinity index is realized by the X-ray diffraction peak height method, and is bulk measurement performed in the dry state. This deficiency can be avoided by solid state ${ }^{13} \mathrm{C}$ nuclear magnetic measurement because the analysis can be conducted in wet state. Nevertheless, there is some evidence that NMR measured crystallinity changes would be similar, the total crystallinity might differ. The characteristic wide angle X-ray scattering patterns were obtained for the "control" and two hydrolysed substrates (not shown in this article). They did not reveal any significant change from the non-hydrolysed substrate for both series. The present results do not indicate an increase of the crystallinity even after more than $70 \%$ of conversion. The most readily accessible molecules are located at the crystal surface, so the macromolecules are hydrolysed one by one and the proportion of amorphous content remains constant during the course of the enzymatic action. This observation supports the erosion mechanism as already described in the literature.

Further structural information can be obtained from neutron contrast variation experiments where the scattering length density (SLD) describes the sum of scattering lengths of all atoms in a volume. The celluloses used in these experiments are Avicel and BSP controls as well as the corresponding $70 \%$ hydrolysed substrates. After swelling in $\mathrm{H}_{2} \mathrm{O} / \mathrm{D}_{2} \mathrm{O}$ mixtures (with volume fractions of $\mathrm{H}_{2} \mathrm{O}: 0,0.25,0.5$ and 0.6 ), the cellulose samples and their slurries were measured in the high $q$ range. The volume fraction of slurries in the cells was determined $a$ posteriori.

Figure 1 represents the square root of scattering intensity for $q=q_{\min }=0.28 \mathrm{~nm}^{-1}$, normalised by the cellulose volume fraction, as a function of the volume fraction of

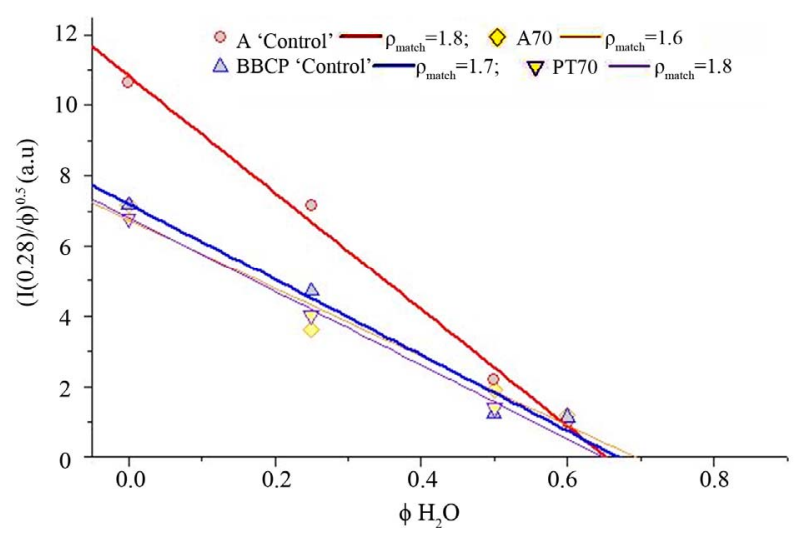

Figure 1. Determination of SLD, at $q=0.28 \mathrm{~nm}^{-1}$, of A and BSP celluloses according to Equation (3bis); grey symbols are for "control" and yellow for $70 \%$ hydrolysed substrates.

$\mathrm{H}_{2} \mathrm{O}$ in the water mixture. According to Equation (3bis), a linear behaviour is observed for all the celluloses. The scattering data around the regression line is attributed to the occurrence of heterogeneities in the cell, leading to small discrepancies between the volume fraction in the cell and in the beam. The water composition at which scattering intensity tends to zero is $65 \%-70 \% \mathrm{H}_{2} \mathrm{O}$. The corresponding scattering length density is $1.6-1.8 \times 10^{10}$ $\mathrm{cm}^{-2}$. In the following sections of the article, we will adopt a unique value of $1.7 \times 10^{10} \mathrm{~cm}^{-2}$. Two conclusions may be drawn from this result: 1) the two cellulosic samples are found to have the same scattering length density, 2) No definitive trend towards hydrolysis is found, which means that the hydrolysed and remaining parts of cellulose particles have the same composition.

The length scale at which cellulose modifications occur is provided by the joint use of the X-ray scattering experiments which cover a broad range of $q$. The scattering curves of the two celluloses and their corresponding partially hydrolysed substrates are shown on Figure 1. The control substrates behave the same way and their scattering curves may be divided as follows:

Region I: at $10^{-3}<\mathrm{q}<0.2 \mathrm{~nm}^{-1}$, the intensity displays a $q$ power law (Equation (3ter)) with an exponent of -3.58 for Avicel and -3.59 for BSP. This power law behavior over two orders of magnitude of $q$ is reminiscent of a surface fractal behaviour. The particle surface fractal dimension is found to be 2.42 for Avicel and 2.41 for BSP.

Region II: at $0.2<q<3 \mathrm{~nm}^{-1}$, an excess of scattering ending with a $q^{-4}$ dependence is observed. This behaviour is ascribed (Equation (4)) to smooth interfaces between water and small objects: the microfibrils.

Region III: at $3<q<10 \mathrm{~nm}^{-1}$, the intensity is very low (few $10^{-2} \mathrm{~cm}^{-1}$ ) and nearly constant. This part of the curve is due to the solvent and is related to its isotherm compressibility. 
Region IV: at $10<q<40 \mathrm{~nm}^{-1}$, Bragg peaks of cellulose superimposed on the classical peak of water. The relative intensities of the Bragg peaks are similar to those recorded by X-ray diffraction for the powder samples. This observation shows that cellulose nanocrystals are not affected by water, somehow in agreement with the finding reported recently showing a minimal effect from two solvation shells on the diffraction patterns of modelled cellulose crystals [58].

In the course of the hydrolysis, the high $q$ region $(q>$ $0.2 \mathrm{~nm}^{-1}$ ) does not vary. By contrast, the exponent power law in the small $q$ region $\left(q<0.2 \mathrm{~nm}^{-1}\right)$ changes from -3.59 for BSP control to -4.0 for BSP $70 \%$ hydrolysed
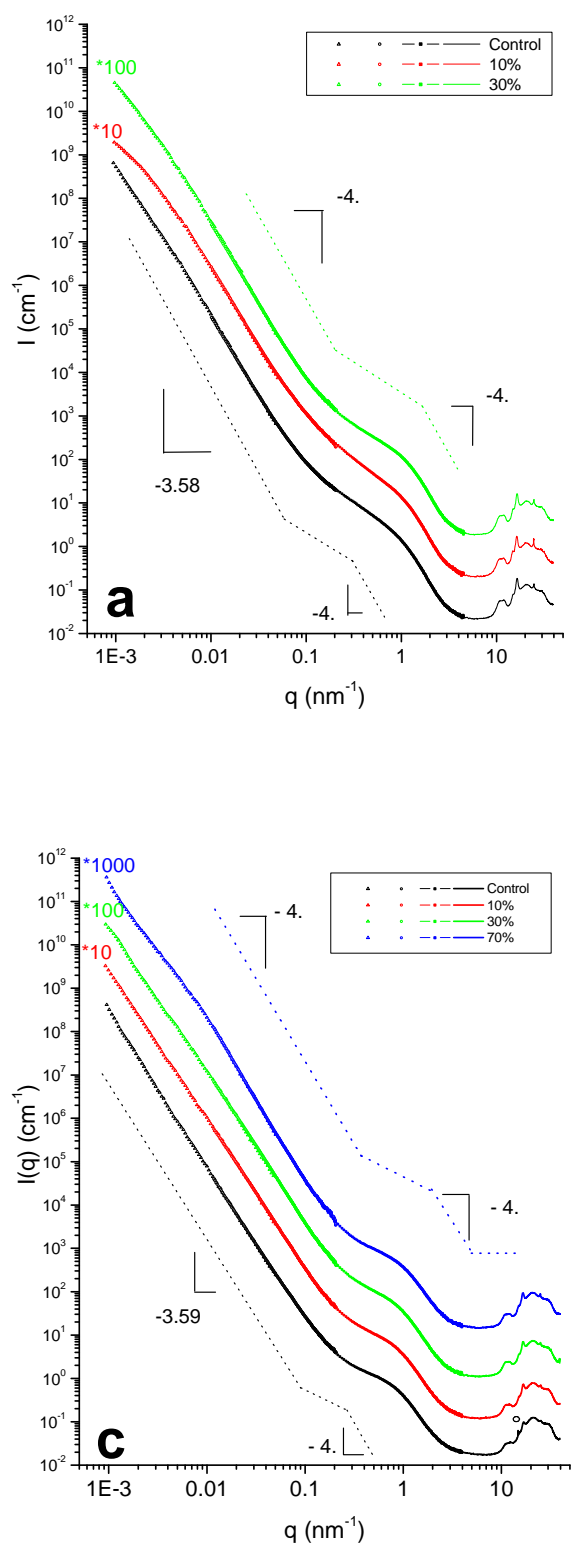

(Figure 2). This behaviour indicates clearly a smoothing of the rough surfaces $[59,60]$. A "Porod" plot, i.e. a $q^{4} I(q)$ versus $q$ plot, is shown for BSP substrates on Figure 2(d). For clarity, the WAXS data are not taken into consideration and the plateau value of region III has been subtracted to small $q$ data. Intensities of partially hydrolysed substrates have been scaled in the high $q$ region to the one of control cellulose by applying a multiplication factor between 0.7 and 1.1. As the hydrolysis proceeds, a clear plateau appears, ending at decreasing $q$ values noted $q_{1}, q_{2}$ and $q_{3}$ for $10 \%, 30 \%$ and $70 \%$ of hydrolysis, respectively. These $q_{\mathrm{n}}$ values are related to the length scale $\xi_{n}$ at which cellulose/water interface is considered
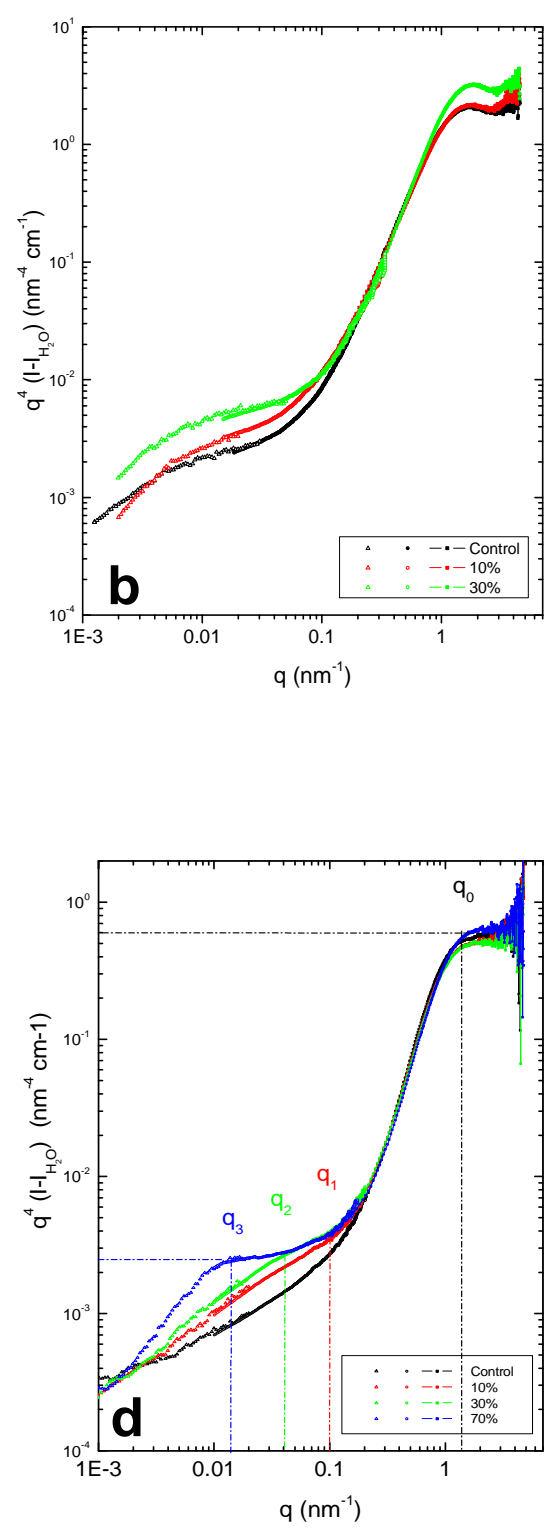

Figure 2. SAXS log/log plot or "Porod" plot of "control" or partially hydrolysed celluloses ((a) and (b) Avicel; (c) and (d) BSP); The different configurations appear in the representations: hollow triangles: USAXS, hollow circles: SAXS1, full squares: SAXS2 and lines: WAXS. 
as smooth. The order of magnitude of $\xi$ is 10,25 and 100 $\mathrm{nm}$ for $10 \%, 30 \%$ and $70 \%$ hydrolysis respectively. The same trend is observed for Avicel cellulose but to a lower extent. These observations demonstrate that most of the enzyme action occurs at the water particle interface, smoothing more and more the rough cellulose surfaces. Unfortunately, the measurement of surface area using the SAXS data is made difficult because the volume fraction in the beam is not accurate.

The variation of the surface area of the substrates occurring in the course of the enzymatic degradation can be characterized from the results of the SANS experiments performed in strong contrast conditions $\left(100 \% \mathrm{D}_{2} \mathrm{O}\right)$ is used. The SANS curves of Avicel (Figure 3) display two $q$ power laws as evidenced by SAXS.

At large $q$ values, $q^{-4}$ behaviour are observed, allowing a determination of the pre-factor A of Equation (4). The knowledge of both the accurate volume fraction of particles and the cellulose scattering length density $\left(\rho_{\text {cellulose }}=1.7 \times 10^{10} \mathrm{~cm}^{-2}, \rho_{\mathrm{D}_{2} \mathrm{O}}=6.37 \times 10^{10} \mathrm{~cm}^{-2}\right)$ provides a way to estimate the Surface/Volume ratio of one average particle. Modelling microfibrils as infinite cylinders (radius $\mathrm{R}_{1}$, length $\mathrm{L}_{1}, \mathrm{~L}_{1}>\mathrm{R}_{1}$ ) allows estimation of an approximate size $\mathrm{R}_{1}$ from Surface/Volume $(\approx$ $\left.2 / R_{1}\right)$. Calculated radius values are reported in Table 1 . Mean values of 3.3 and $5 \mathrm{~nm}$ respectively for Avicel and
BSP are in close agreement with the diameter of wood microfibrils estimated at $3.5 \mathrm{~nm}$ by Pérez and Samain [18]. Moreover, each value remains rather constant during the course of the hydrolysis, indicating that there is no modification of the surface area of the microfibrils.

At small $q$ values $\left(q<0.1 \mathrm{~nm}^{-1}\right)$, a $q^{-4}$ behaviour is observed for $30 \%$ and $70 \%$ hydrolysis while smaller exponents are recorded for control and $10 \%$. For sake of simplicity, this q region has been fit to Porod's law (Equation (4)) whatever the conversion is. The same approach has been applied to determine the approximate sizes $R_{2}$ of cellulose particles, providing particles as infinite cylinders. The reported values in Table $\mathbf{1}$ are in the micron range in accordance with the measurements performed with the Flow Particles Image Analyser. A clear decrease of the particle radius with conversion is observed both for Avicel and BSP substrates, confirming that enzyme action occurs at water/particle interface. These results may contain some experimental errors. The main source of error comes from the determination of the volume fractions of cellulose in the measurement cells. The dry matter content was determined after the measurement and it is likely that there is some evaporation during the analysis. Moreover, it is not guaranteed that the sample was totally homogeneous in the cell. We also used the same scattering length density for the microfibrils and
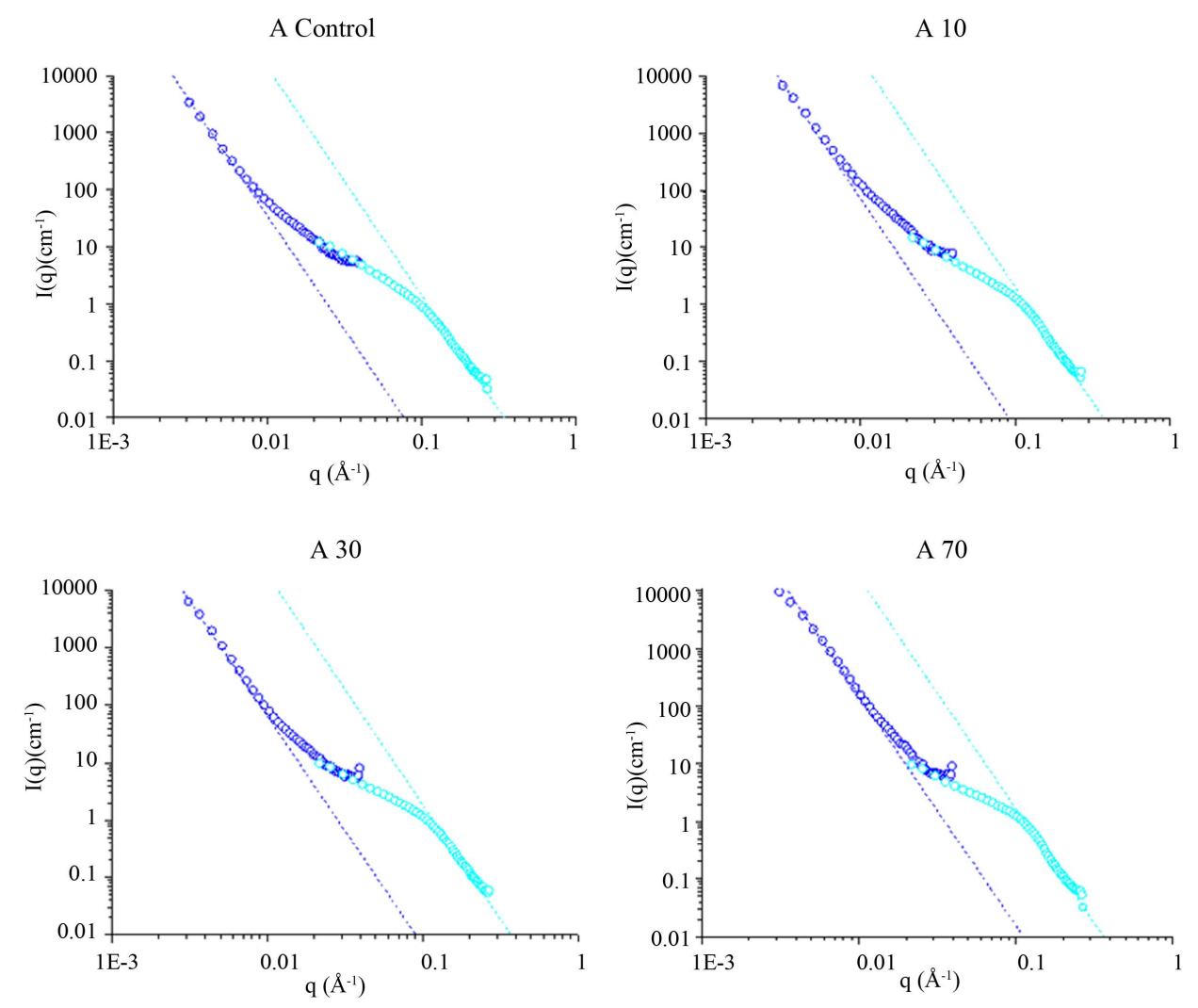

Figure 3. Neutron scattering data from control and hydrolysed substrates from Avicel. 
the fibers. However, water cannot penetrate into the microfibrils which are very crystalline whereas water can penetrate into the amorphous part of microfibrils and can modify cellulose scattering length density. The global error was estimated to $\sim 12 \%$. There is no significant change in the microfibril radius between the "control" substrate and the partially hydrolysed substrates from both Avicel and BSP, which indicates that there is no evolution in cellulose nanostructure. These results confirm the unaltered degrees of crystallinity. Finally, enzymes degrade cellulose layer by layer, microfibril by microfibril and the observation of the surface at the nanometre scale does not reveal any change during the reaction.

The micrometer size structure can be observed on SEM images (Figure 4) for enzymatically hydrolysed substrates at different conversions. Comparing both
Avicel and BSP "control" substrates, Avicel has significantly smaller particles than BSP. A decrease of the particle size between intact and hydrolysed cellulose was also observed but must be confirmed by measuring cellulose particle size. The MorFi analyser was used to distinguish between BSP fibers, having dimensions greater than $80 \mu \mathrm{m}$, and fine elements with a length below 80 $\mu \mathrm{m}$. Figure 5 presents the evolution of particle length for control and 70\% hydrolysed BSP substrates. There is a clear decrease of fiber length for particles which are longer than $80 \mu \mathrm{m}$ as well as there is a decrease of the percentage of particles measuring more than $80 \mu \mathrm{m}$. Even if small angle scattering analyses have shown that enzymes cannot penetrate the cellulose structure, cellulose may contain easily hydrolysable fractions which are initially hydrolysed, leading to a decrease of average particle length.
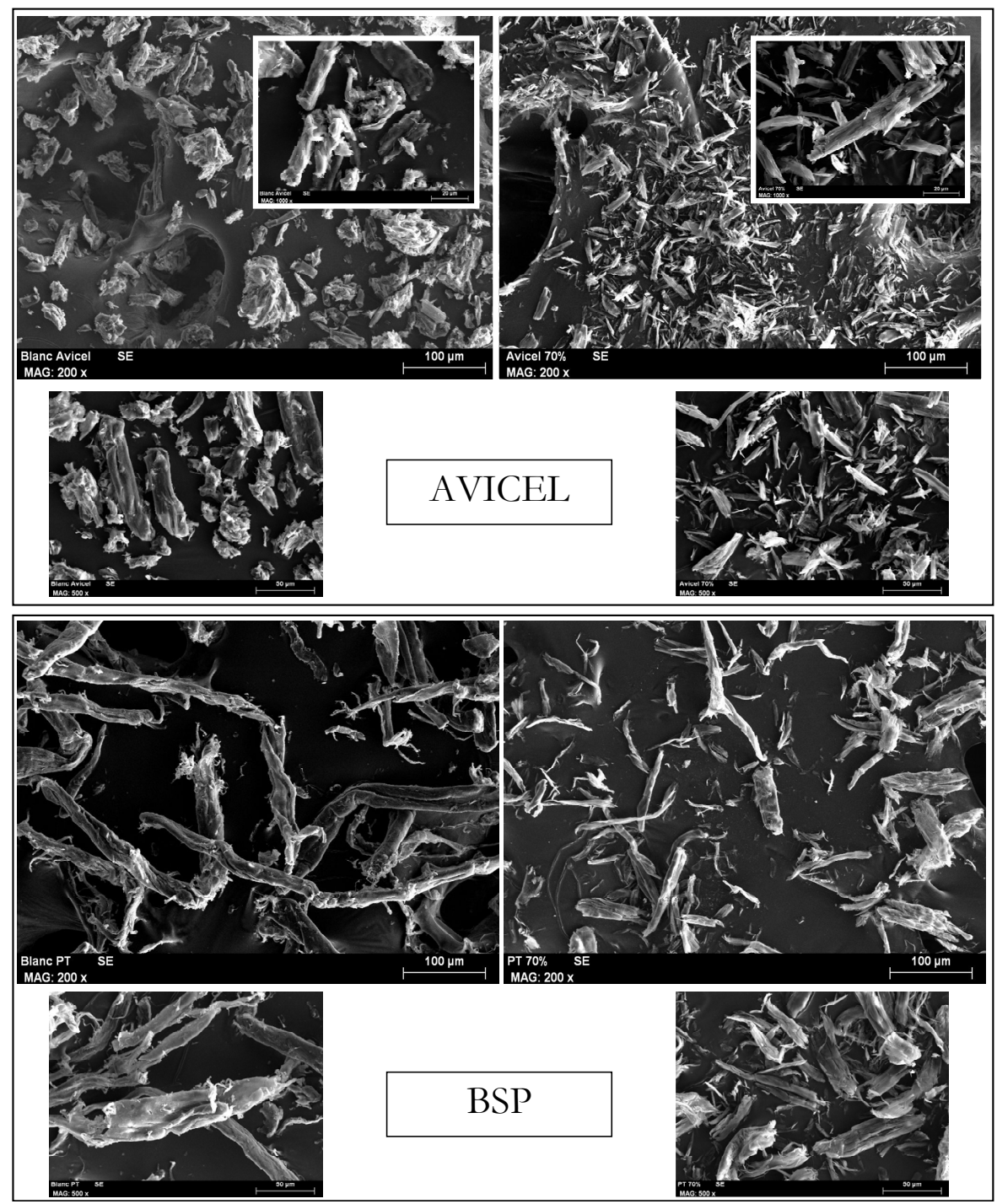

Figure 4. SEM picture of partially hydrolysed cellulose at various conversion for two different cellulosic substrates. 


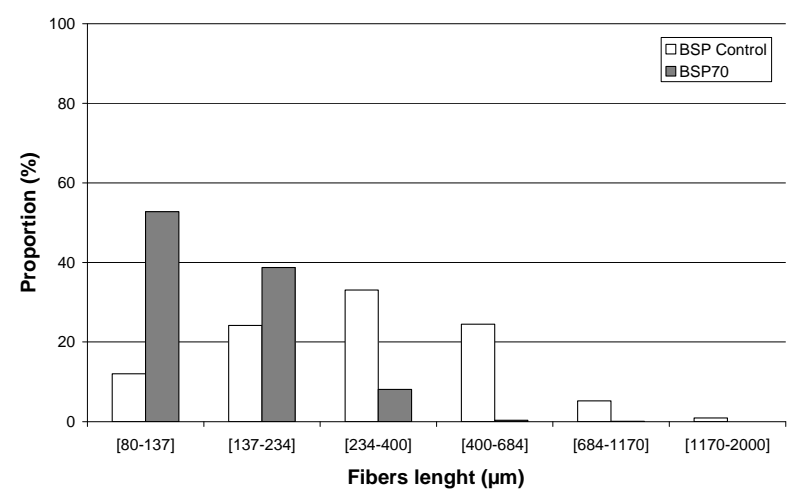

Figure 5. Evolution of particle size for hydrolysed substrate from BSP.

To confirm this mechanism in the case of Avicel, particle sizes were determined using a Flow Particles Image Analyser (FPIA) which is most adequate to assess the dimensions of small particles having length between 1 to $100 \mu \mathrm{m})$. Calculated arithmetic average length and width are presented in Table 1. Particles of the control substrates from BSP were not measured due to their relatively large sizes. Results for partially hydrolysed substrates prepared from Avicel are presented in Figure 6. A clear decrease of the average width of particles is observed whereas the length seems to remain unchanged. Enzymatic hydrolysis occurs at particle surfaces leading to a decrease in particle width. This mechanism is different from the hydrolysis of BSP substrates because a decrease in particle length is not observed.

As microfibrils are surrounded by non-crystalline or para-crystalline chains distributed in their outer wall, a two-phase mechanism, already illustrated in the literature [25] can be proposed to explain this observation. During the first phase, the most reactive parts of cellulose (amorphous and para-crystalline) are hydrolysed and cellulose may be cut into small segments. During the second phase, enzyme attack mainly occurs at the exposed crystalline surface leading to the erosion of particles.

\subsection{Reactivity of Cellulosic Substrates during Saccharification}

The reactivity of partially hydrolysed substrates was evaluated throughout initial apparent kinetic assays. Restart activity was determined by measuring the amount of glucose released after 30 min using fresh enzymatic cocktails. Relative reactivity was calculated for both series of partially hydrolysed substrates by comparison with the untreated controls (Table 2).

For both substrates a slight decrease of restart activity, from $10 \%$ to $30 \%$, was correlated to the level of partial hydrolysis rate for partial hydrolyses of $10 \%$ to $70 \%$, respectively. These results may be explained by the occur-
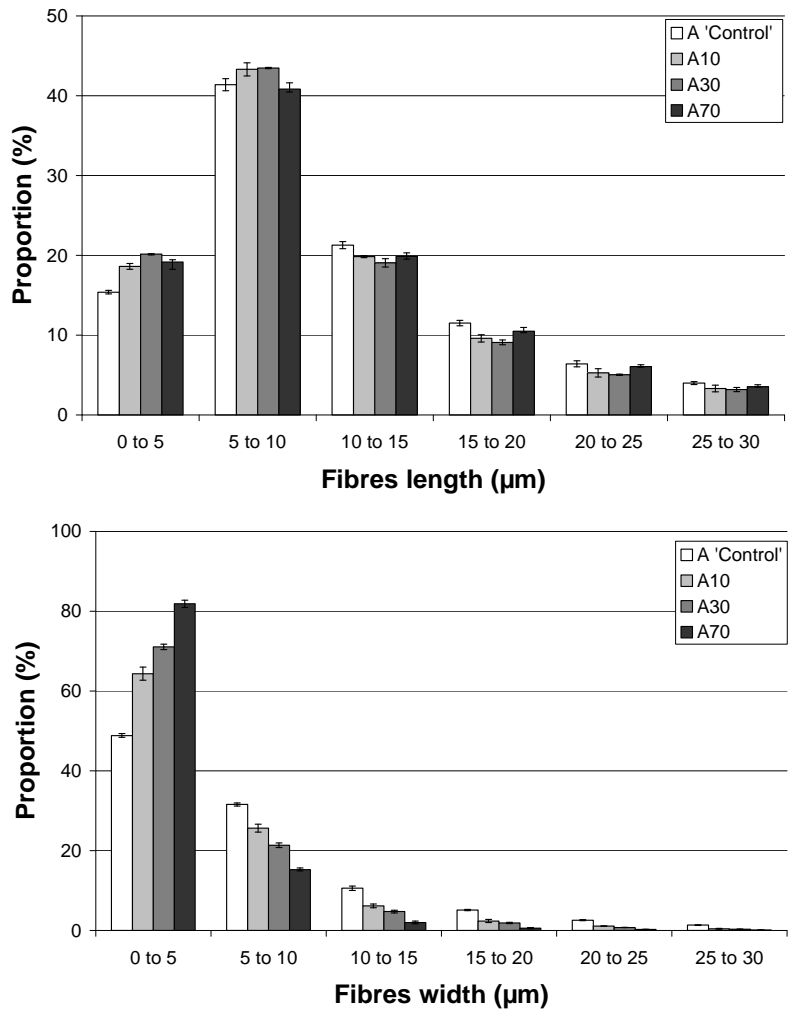

Figure 6. Evolution of fibre length and width for partially hydrolysed substrate from Avicel.

Table 2. Evolution of substrate reactivity during conversion of Avicel and BSP cellulosic substrates.

\begin{tabular}{ccccc}
\hline Substrate (Serie I) & BA & A10 & A30 & A70 \\
\hline $\begin{array}{c}\text { Initial hydrolysis rate } \\
\left(\mathrm{g}_{\text {glucose }} \cdot \mathrm{h}^{-1} \cdot \mathrm{g}_{\text {enzyme }}{ }^{-1}\right)\end{array}$ & 3.9 & 3.6 & 3.4 & 2.7 \\
$\begin{array}{c}\text { Hydrolysis rate of BA } \\
\text { at the corresponding } \\
\text { conversion }\end{array}$ & 3.9 & 3.0 & 1.8 & 0.3 \\
$\begin{array}{c}\left(\mathrm{g}_{\text {glucose }} \cdot \mathrm{h}^{-1} \cdot \mathrm{g}_{\text {enzyme }}{ }^{-1}\right) \\
\quad \begin{array}{c}\text { Substrate } \\
(\text { Serie II) }\end{array}\end{array}$ & BSP & BSP10 & BSP30 & BSP70 \\
$\begin{array}{c}\text { Initial hydrolysis rate } \\
\left(\mathrm{g}_{\text {glucose }} \cdot \mathrm{h}^{-1} \cdot \mathrm{g}_{\text {enzyme }}{ }^{-1}\right)\end{array}$ & 3 & 2.5 & 2.2 & 2.0 \\
$\begin{array}{c}\text { Hydrolysis rate of BSP } \\
\text { at the corresponding } \\
\text { conversion }\end{array}$ & 3 & 1.5 & 1 & 0.25 \\
$\left(\mathrm{~g}_{\text {glucose }} \cdot \mathrm{h}^{-1} \cdot \mathrm{g}_{\text {enzyme }}{ }^{-1}\right)$ & & & & \\
\hline
\end{tabular}

rence of several levels of interactions in the fiber network. The most reactive fractions of cellulose may be located at the surface of the cellulose architecture revealing a more resistant substrate during the enzymatic hydrolysis. 
The loss of substrate reactivity was assessed by the global kinetic tests. Table 2 shows the evolution of the hydrolysis rate during uninterrupted and restart experiments for Avicel and BSP cellulosic substrates. Results indicate a systematically higher degradation rate for Avicel than for BSP. This may be explained by the tenfold lower average DP for Avicel resulting in the formation of smaller particles and higher surface area. The rate for interrupted experiments dropped rapidly with around $50 \%$ of loss after only $25 \%$ of conversion. However, by comparing uninterrupted and restart experiments, the loss of substrate reactivity cannot fully explain the decrease of the conversion rate suggesting that others factors such as enzyme deactivation and product inhibition are also involved [55].

\section{DISCUSSION}

In this work, the evolutions of cellulosic substrate morphology and reactivity were studied as a function of enzymatic conversion. Partially hydrolysed substrates have been prepared to investigate the structural and morphological changes at different length scales using various characterization methods such as viscosity measurement, WAXS, SAXS, SANS and particles size analyser.

In agreement with previous reports $[28,29]$ the viscosity measurements did not indicate any change of the degree of polymerization in the course of enzymatic hydrolysis. With regard to the cellulose nanostructure, the crystallinity of partially hydrolysed samples remained unaltered during hydrolysis. SANS measurements confirmed the unmodified size of cellulose microfibrils all along the course of the enzymatic reaction. Earlier results already showed that the crystallinity remains unchanged during hydrolysis $[14,36]$. Based on these results, we surmise that the microfibrillar architecture remains intact during hydrolysis. As for the cellulose microstructure, small angle scattering results have shown an increase of surface area with the conversion whereas the particle size analyses showed decreases in particles size. It appears clearly that enzymatic hydrolysis occurs at particle surfaces and that enzymes are not able to penetrate the cellulose crystalline structure.

The mechanisms involved during the enzymatic hydrolysis remain to be clarified. As for the hydrolysis of BSP, a decrease of particle length was observed whereas, for Avicel, particle length remains constant and particle width decreases. The main differences between these two substrates are their initial sizes; the BSP particles are tenfold larger than those in Avicel. In their studies, Thygesen et al. [61] and Clarke et al. [62] observed a mechanism of fiber cutting, on pre-treated wheat straw as well as on bleached softwood Kraft pulp. For both substrates, major changes in particle size occur during the 6 - 8 first hours of the reaction and then particle length decreases very slowly or remains constant. It should be noted that enzymes can also cause the well-known levelling-off phenomenon. Both studies show that the fiber cutting occurs at dislocation sites yielding a more reactive substrate [62]. Our results on BSP do confirm the fiber-cutting phenomenon, but in the case of Avicel particles, only a decrease in particle width occurred. A possible mechanism for the enzymatic hydrolysis consists in a two-step process of fiber cutting and particle erosion. During the first part of the reaction, long cellulosic fibers are first cut in small segments mainly in dislocation points and this action leads to small particles. Then, enzyme attack occurred at the surface of the particles with an erosive mechanism. In this case, particle length remains relatively constant whereas the width decreases. In our experiments, BSP particles follow this two-step mechanism whereas only particle erosion can be observed for Avicel particles.

The evolution of substrate reactivity during enzymatic hydrolysis is considered to have a negative impact on the rate of hydrolysis. The present study indicates a decrese of the substrate reactivity for both low- and high-degree of polymerisation. By comparing reaction rates of uninterrupted and restart experiments the loss of substrate reactivity cannot explain the global decrease of the reaction rate. It is nevertheless important to consider the losses in substrate reactivity as they represent $20 \%$ for a substrate that has been $70 \%$ converted. Substrate morphology analysis has shown that partially hydrolysed substrates have smaller particles and higher surface area. Increasing the surface area should lead to an increase of enzyme adsorption and a concomitant increase of the reaction rate. However, a decrease of the reactivity is found for partially hydrolysed substrates and the morphological changes cannot explain this observation. It may be advocate that the edge of the particles are more reactive than the core, which is more organized. Wang et $a l$. [35] proposed that changes in the packing of microfibrils may be responsible for the decrease of the reaction rate. Small angle scattering results have revealed a smoothing of the rough cellulose surface and even if there is an increase in the available surface its smoothing can lead to a decrease of cellulose accessibility thereby impacting the reactivity of the substrate. Igarashi et al. [4] have highlighted the capacity of CBHI (Cel7A) from Trichoderma reesei to cause morphological changes to bacterial cellulose. Real-time AFM imaging has revealed the selective hydrolysis of the hydrophobic faces of bacterial cellulose by this exo-cellulase. The action of endoglucanase CeL7B on cellulose architecture was also recently investigated by real-time AFM [27] yielding similar results.

As the reaction proceeds, conversion should also be correlated with a loss in volume. The volume losses 
measured by SANS and FPIA, for the partially hydrolysed substrates prepared from Avicel, and only measured by SANS, for the BSP, are presented in Figure 7. The black line represents the loss of volume considering that it is proportional to the conversion rate. Interestingly, for both substrates, a large decrease of the volume is observed at the first stage of the reaction compared to what was expected. Then, the decrease of the volume seems to follow the rate of the conversion. One hypothesis should be that, at the beginning, enzymes are disrupting the particle agglomerates before really starting to erode particles. Another explanation could be a difference of density between the core and the edge of the particles, with a better organisation in the core even if this explanation seems less likely regarding density measurement.

\section{CONCLUSIONS}

It was the aim of the present work to understand the mechanisms involved in cellulose degradation by cellulolytic enzymes. A particular emphasis was given to the identification of the changes in substrate morphology and reactivity during the course of the reaction. Partially hydrolysed of a low- and a high DP cellulosic substrates were used to follow the evolution of substrate properties. Results showed that there is no change at the nanometer scale whereas the structural features at the micron scale are clearly impacted. A decrease in particles size, and consequently an increase in the surface area is observed and ascribed to a smoothing of the cellulose surface. A two-step mechanism for the enzymatic hydrolysis is proposed to explain the observed phenomena: 1) fibers are cut into small particles which have a minimum size, 2) particles are eroded at the surface as enzymes are unable to penetrate the cellulose structure.

A decrease in the reactivity of cellulose has been observed which cannot explain totally the loss in reaction rate during the enzymatic hydrolysis. A correlation between the substrate morphology and the changes in reac-

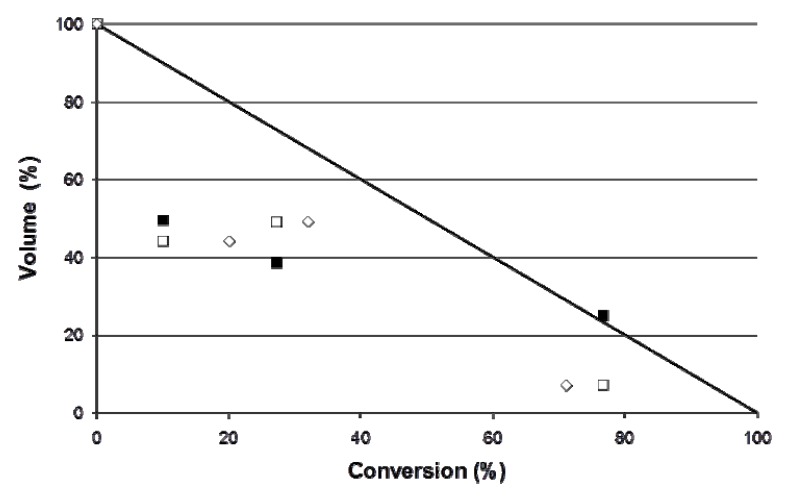

Figure 7. Loss of volume as a function of conversion substrate from Avicel measured by FPIA ( $\square$ ) and measured by SANS ( $\square$ ). Substrate from Pâte de Tartas measured by SANS $(\diamond)$. tivity does not stand as the surface area increase does not lead to an increase of the reactivity but to a decrease. Moreover, the volume loss during the conversion is more important than initially expected by considering a linear relationship between conversion and particles volume. The smoothing of cellulose surface may explain the decrease of cellulose accessibility. The edge of the particles is more reactive and less dense whereas the core is less reactive and denser. However, this question needs more investigation to better understand the impact of the substrate properties during enzymatic hydrolysis.

\section{ACKNOWLEDGEMENTS}

The financial support from ADEME for a doctoral fellowship to M.C. is gratefully acknowledged. Acknowledgements are extended to the European Synchrotron Radiation Facility, Grenoble, France, for accessing the beam line IDO2 and to the Laboratoire Leon Brillouin, Saclay, France for the Neutron measurements on the PAXE instrument.

\section{REFERENCES}

[1] Foust, T.S., Ibsen, K.N., Dayton, D.C., Hess, J.R. and Kenney, K.E. (2008) The biorefinery. In: Himmel, M.E. Ed., Biomass Recalcitrance: Deconstructing the Plant Cell Wall for Bioenergy, Wiley-Blackwell, 7-35.

[2] Margeot, A., Hahn-Hagerdal, B., Edlund, M., Slade, R. and Monot, F. (2009) New improvements for lignocellulosic ethanol. Current Opinion Biotechnology, 20, 372 380. http://dx.doi.org/10.1016/j.copbio.2009.05.009

[3] Bansal, P., Hall, M., Realff, M.J., Lee, J.H. and Bommarius, A.S. (2009) Modeling cellulase kinetics on lignocellulosic substrates. Biotechnology Advances, 27, 833848. http://dx.doi.org/10.1016/j.biotechadv.2009.06.005

[4] Igarashi, K., Uchihashi, T., Koivula, A., Wada, M., Kimura, S., Okamoto, T., Penttila, M., Ando, T. and Samejima, M. (2011) Traffic jams reduce hydrolytic efficiency of cellulase on cellulose surface. Science, 333, 12791282. http://dx.doi.org/10.1126/science. 1208386

[5] Medve, J., Stahlberg, J. and Tjerneld, F. (1994) Adsorption and synergism of cellobiohydrolase I and II of Trichoderma reesei during hydrolysis of microcrystalline cellulose. Biotechnology and Bioengineering, 44, 10641073. http://dx.doi.org/10.1002/bit.260440907

[6] Boisset, C., Petrequin, C., Chanzy, H., Henrissat, B. and Schulein, M. (2001) Optimized mixtures of recombinant Humicola insolens cellulases for the biodegradation of crystalline cellulose. Biotechnology and Bioengeneering, 72, 339-345.

http://dx.doi.org/10.1002/1097-0290(20010205)72:3<339 :AID-BIT11>3.0.CO;2-\#

[7] Nimlos, M.R., Matthews, J.F., Crowley, M.F., Walker, R.C., Chukkapalli, G., Brady, J.W., Adney, W.S., Cleary, J.M., Zhong, L. and Himmel, M.E. (2007) Molecular modeling suggests induced fit of Family I carbohydratebinding modules with a broken-chain cellulose surface. Protein Engineering, 20, 179-187. 
http://dx.doi.org/10.1093/protein/gzm010

[8] Tavagnacco, L., Mason, P.E., Schnupf, U., Pitici, F., Zhong, L., Himmel, M.E., Crowley, M., Cesaro, A. and Brady, J.W. (2011) Sugar-binding sites on the surface of the carbohydrate-binding module of CBH I from Trichoderma reesei. Carbohydrate Research, 346, 839-846. http://dx.doi.org/10.1016/j.carres.2011.01.019

[9] Converse, A.O., Matsumo, R., Tanaka, M. and Taniguchi, M. (1988) A model of enzyme adsorption and hydrolysis of microcrystalline cellilose with slow desactivation of the adsorbed enzyme. Biotechnology and Bioeengineering, 32, 38-45. http://dx.doi.org/10.1002/bit.260320107

[10] Eriksson, T., Karlsson, J. and Tjerneld, F. (2002) A model explaining declining rate in hydrolysis of lignocellulose substrates with cellobiohydrolase I (cel7A) and endoglucanase I (cel7B) of Trichoderma reesei. Applied Biochemistry Biotechnology, 101, 41-60. http://dx.doi.org/10.1385/ABAB:101:1:41

[11] Holtzapple, M., Cognata, M., Shu, Y. and Hendrickson, C. (1990) Inhibition of Trichoderma reesei cellulase by sugars and solvents. Biotechnology and Bioengineering, 36, 275-287. http://dx.doi.org/10.1002/bit.260360310

[12] Zhang, S., Wolfgang, D.E. and Wilson, D.B. (1999) Substrate heterogeneity causes the nonlinear kinetics of insoluble cellulose hydrolysis. Biotechnology and Bioeengineering, 66, 35-41.

http://dx.doi.org/10.1002/(SICI)1097-0290(1999)66:1<35 $\because$ AID-BIT3>3.0.CO;2-G

[13] Fan, L.T., Lee, Y.H. and Beardmore, D.H. (1980) Mechanism of the enzymatic-hydrolysis of cellulose. Effects of major structural features of cellulose on enzymatic hydrolysis. Bioetchnology and Bioengineering, 22, 177-199. http://dx.doi.org/10.1002/bit.260220113

[14] Hall, M., Bansal, P., Lee, J.H., Realff, M.J. and Bommarius, A.S. (2010) Cellulose crystallinity-A key predictor of the enzymatic hydrolysis rate. FEBS Journal, 277, 1571-1582.

[15] Nishiyama, Y. (2009) Structure and properties of the cellulose micorfibril. Journal Wood Sciences, 55, 241249. http://dx.doi.org/10.1007/s10086-009-1029-1

[16] Somerville, C., Bauer, S., Brininstool, G., Facette, M., Hamann, T., Milne, J., Osborne, E., Paredez, A., Persson, S., Raab, T., Vorwerk, S. and Youngs, H. (2004) Toward a systems approach to understanding plant cell walls. Science, 306, 2206-2211. http://dx.doi.org/10.1126/science.1102765

[17] Bayer, E.A., Chanzy, H., Lamed, R. and Shoham, Y. (1998) Cellulose, cellulases and cellulosomes. Current Opinion Structural Biology, 8, 548-557. http://dx.doi.org/10.1016/S0959-440X(98)80143-7

[18] Perez, S. and Samain, D. (2010) Structure and engineering of celluloses. Advances Carbohydrate Chemistry Biochemistry, 64, 25-116.

[19] Nishiyama, Y., Sugiyama, J., Chanzy, H. and Langan, P. (2003) Crystal structure and hydrogen bonding system in cellulose I(alpha) from synchrotron X-ray and neutron fiber diffraction. Journal American Chemical Society, 125, 14300-14306. http://dx.doi.org/10.1021/ja037055w

[20] Larsson, P.T., Hult, E.L., Wickholm, K., Pettersson, E. and Iversen, T. (1999) CP/MAS 13C-NMR spectroscopy applied to structure and interaction studies on cellulose I. Solid State Nuclear Magnetic Resonance, 15, 31-40. http://dx.doi.org/10.1016/S0926-2040(99)00044-2

[21] Mansfield, S.D., Mooney, C. and Saddler, J.N. (1999) Substrate and enzyme characteristics that limit cellulose hydrolysis. Biotechnology Progress, 15, 804-816. http://dx.doi.org/10.1021/bp9900864

[22] Jeoh, T., Ishizawa, C.I., Davis, M.F., Himmel, M.E., Adney, W.S. and Johnson, D.K. (2007) Cellulase digestibility of pretreated biomass is limited by cellulose accessibility. Biotechnology and Bioenginnering, 98, 112-122. http://dx.doi.org/10.1002/bit.21408

[23] Bommarius, A.S., Katona, A., Cheben, S.E., Patel, A.S., Ragauskas, A.J., Knudson, K. and Pu, Y. (2008) Cellulase kinetics as a function of cellulose pretreatment. $\mathrm{Me}$ tabolic Engineering, 10, 370-381. http://dx.doi.org/10.1016/j.ymben.2008.06.008

[24] Zhang, Y.H. and Lynd, L.R. (2006) A functionally based model for hydrolysis of cellulose by fungal cellulase. Biotechnology and Bioeengineering, 94, 888-898. http://dx.doi.org/10.1002/bit.20906

[25] Arantes, V. and Saddler, J.N. (2010) Access to cellulose limits the efficiency of enzymatic hydrolysis: The role of amorphogenesis. Biotechnology Biofuels, 3, 4. http://dx.doi.org/10.1186/1754-6834-3-4

[26] Zhong, L., Matthews, J.F., Hansen, P.I., Crowley, M.F., Cleary, J.M., Walker, R.C., Nimlos, M.R., Brooks 3rd, C.L., Adney, W.S., Himmel, M.E. and Brady, J.W. (2009) Computational simulations of the Trichoderma reesei cellobiohydrolase I acting on microcrystalline cellulose Ibeta: The enzyme-substrate complex. Carbohydrate Research, 344, 1984-1992.

http://dx.doi.org/10.1016/j.carres.2009.07.005

[27] Wang, J., Quirk, A., Lipkowski, J., Dutcher, J.R., Hill, C., Mark, A. and Clarke, A.J. (2012) Real-time observation of the swelling and hydrolysis of a single crystalline cellulose fiber catalyzed by cellulase $7 \mathrm{~B}$ from Trichoderma reesei. Langmuir, 28, 9664-9672. http://dx.doi.org/10.1021/la301030f

[28] Walseth, C.S. (1957) The influence of the fine structure of cellulose on the action of cellulases. TAPPI, 35, 233238.

[29] Phillipp, B., Dan, C.D. and Fink, F.H.-P. (1981) Acid and enzymatic hydrolysis of cellulose in relation to its physical structure. Proceedings International Symposium on Wood and Pulping Chemistry, 4, 79-83.

[30] Gupta, R. and Lee, Y.Y. (2009) Mechanism of cellulase reaction on pure cellulosic substrates. Biotechnology and Bioengineering, 102, 1570-1581. http://dx.doi.org/10.1002/bit.22195

[31] Sinitsyn, A.P., Mitkevich, O.V., Giusakov, A.V. and Klyosov, A.A. (1989) Decrease in reactivity and change of physico-chemical parameters of cellulose in the course of enzymatic hydrolysis. Carbohydrate Polymers, 10, 114. http://dx.doi.org/10.1016/0144-8617(89)90028-3

[32] Reese, E.T., Segal, L. and Tripp, V.W. (1957) The effect of cellulase on the degree of polymerization of cellulose and hydrocellulose. Textile Research Journal, 27, 626- 


\section{2. http://dx.doi.org/10.1177/004051755702700806}

[33] Chen, Y., Stipanovic, A.J., Winter, W.T., Wilson, D.B. and Kim, Y.J. (2007) Effect of digestion by pure cellulases on crystallinity and average chain length for bacterial and microcrystalline celluloses. Cellulose, 14, 283293. http://dx.doi.org/10.1007/s10570-007-9115-2

[34] Zhang, Y.H. and Lynd, L.R. (2004) Toward an aggregated understanding of enzymatic hydrolysis of cellulose: noncomplexed cellulase systems. Biotechnology and Bioeengineering, 88, 797-824. http://dx.doi.org/10.1002/bit.20282

[35] Wang, L.S., Zhang, Y.Z., Gao, P.J., Shi, D.X., H.W., L. and Gao, H.L. (2006) Changes in the structural properties and rate of hydrolysis of cotton fibers during extended enzymatic hydrolysis. Biotechnology and Bioeengineering, 93, 443-456.

[36] Penttila, P.A., Varnai, A., Leppanen, K., Peura, M., Kallonen, A., Jaaskelainen, P., Lucenius, J., Ruokolainen, J., Siika-Aho, M., Viikari, L. and Serimaa, R. (2010) Changes in submitcrometer structure of enzymatically hydrolyzed microcrystalline cellulose. Biomacromolecules, 11, 1111-1117. http://dx.doi.org/10.1021/bm1001119

[37] Kent, M.S., Cheng, G., Murton, J.K., Carles, E.L., Dibble, D.C., Zendejas, F., Rodriquez, M.A., Tran, H., Holmes, B., Simmons, B.A., Knierim, B., Auer, M., Banuelos, J.L., Urquidi, J. and Hjelm, R.P. (2010) Study of enzymatic digestion of cellulose by small angle neutron scattering. Biomacromolecules, 11, 357-368. http://dx.doi.org/10.1021/bm9008952

[38] Cheng, G., Varanasi, P., Li, C., Liu, H., Melnichenko, Y.B., Simmons, B.A., Kent, M.S. and Singh, S. (2011) Transition of cellulose crystalline structure and surface morphology of biomass as a function of ionic liquid pretreatment and its relation to enzymatic hydrolysis. Biomacromolecules, 12, 933-941. http://dx.doi.org/10.1021/bm101240z

[39] Park, S., Venditti, R.A., Abrecht, D.G., HJammel, H., Pawlak, J.J. and Lee, J.M. (2007) Surface and Pore Structure Modification of Cellulose Fibers Through Cellulase Treatment. Journal of Applied Polymer Sciences, 103, 3833-3839. http://dx.doi.org/10.1002/app.25457

[40] Desai, S.G. and Converse, A.O. (1997) Substrate reactiveity as a function of the extent of reaction in the enzymatic hydrolysis of lignocellulose. Biotechnology and Bioengineering, 56, 650-655.

http://dx.doi.org/10.1002/(SICI)1097-0290(19971220)56: 6<650::AID-BIT8>3.0.CO;2-M

[41] Fan, L.T. and Lee, Y.H. (1983) Kinetic studies of enzymatic hydrolysis of insoluble cellulose: Derivation of a mechanistic kinetic model. Biotechnology and Bioengineering, 25, 2707-2733. http://dx.doi.org/10.1002/bit.260251115

[42] Yang, B., Willies, D.M. and Wyman, C.E. (2006) Changes in the enzymatic hydrolysis rate of Avicel cellulose with conversion. Biotechnology and Bioeengineering, 94, 11221128. http://dx.doi.org/10.1002/bit.20942

[43] Durand, H. and Tiraby, G. (2010) 9ième colloque de la Société Française de Microbiologie, 39-50.

[44] Herpoel-Gimbert, I., Margeot, A., Dolla, A., Jan, G., Molle, D., Lignon, S., Mathis, H., Sigoillot, J.C., Monot, F. and Asther, M. (2008) Comparative secretome analyses of two
Trichoderma reesei RUT-C30 and CL847 hypersecretory strains. Biotechnology for Biofuels, 1, 18. http://dx.doi.org/10.1186/1754-6834-1-18

[45] Chauve, M., Lopes Ferreira, N., Casanave, D., Da Silva Perez, D. and Perez, S. (2010) Kinetic modeling of pure cellulases involved in enzymatic hydrolysis of cellulose. 18th European Biomass Conference and Exhibition From Research to Industry and Markets, Lyon, 3-7 May 2010 1380-1387.

[46] Van Nifterik, L., Xu, L., Laurent, J.L., Mathieu, J. and Rakoto, C. (1993) Analysis of cellulose and kraft oulo ozonolysis products by anion-exchange chromatography with pulsed amperometric detection. Journal of Chromatography, 640, 335-343. http://dx.doi.org/10.1016/0021-9673(93)80199-I

[47] Evans, R. and Wallis, A.F.A. (1989) Cellulose molecular weights determined by viscometry. Journal of Applied Polymer Sciences, 37, 2331-2340. http://dx.doi.org/10.1002/app.1989.070370822

[48] Sztucki, M., Gorini, J., Vassalli, J.P., Goirand, L., Van Vaerenbergh, P. and Narayanan, T. (2008) Optimization of a bonse-hart instrument by suppressing surface parasitic scattering. Journal of Synchrotron Radiation, 15, 341349. http://dx.doi.org/10.1107/S0909049508008960

[49] Brulet, A., Lairez, D., Lapp, A. and Cotton, J.P. (2007) Imporvement of data treatment in small-angle neutron scattering. Journal of Applied Crystallography, 40, 165-177. http://dx.doi.org/10.1107/S0021889806051442

[50] Ma, A., Hu, Q., Qu, Y.B., Bai, Z.H., Liu, W.F. and Zhuang, G.Q. (2008) The enzymatic hydrolyis rate of cellulose decreases with reversible adsorption of cellobiohydrolase I. Enzyme and Microbial Technology, 42, 543-547. http://dx.doi.org/10.1016/i.enzmictec.2008.02.009

[51] Hong, J., Ye, X. and Zhang, Y.H. (2007) Quantitative determination of cellulose accessibility to cellulase based on adsorption of a nonhydrolytic fusion protein containing CBM and GFP with its applications. Langmuir, 23, 1253512540. http://dx.doi.org/10.1021/la7025686

[52] Zhu, Z., Sathitsuksanoh, N. and Zhang, Y.H. (2009) Direct quantitative determination of adsorbed cellulase on lignocellulosic biomass with its application to study cellulase desorption for potential recycling. Analyst, 134, $2267-$ 2272. http://dx.doi.org/10.1039/b906065k

[53] Lee, H.J. and Malcolm Brown Jr., R. (1997) A comparative structural characterization of two cellobiohydrolases from Trichoderma reesei: A high resolution electron microscopy study. Journal of Biotechnology, 57, 127-136. http://dx.doi.org/10.1016/S0168-1656(97)00111-9

[54] Walker, L.P., Wilson, D.B., Irvin, D.C., McQuire, C. and Price, M. (1992) Fragmentation of Cellulose by the Major Thermomonospora fusca Cellulases, Trichoderma reesei CBHI, and their Mixtures. Biotechnology and Bioengineering, 40, 1019-1026. http://dx.doi.org/10.1002/bit.260400905

[55] Yu, Z., Jameel, H., Chang, H.M., Philips, R. and Park, S. (2012) Evaluation of the factors affecting avicel reactivity using multi-stage enzymatic hydrolysis. Biotechnology and Bioeengineering, 109, 1131-1139. http://dx.doi.org/10.1002/bit.24386 
[56] Zhong, L., Matthews, J.F., Crowley, F., Rignall, T., Talon, C., Cleary, J.M., Walker, R.C., Chukkapalli, G., McCabe, C., Nimlos, M.R., Brooks, C.L., III, Himmel, M.E. and Brady, J.W. (2008) Interactioons of the complete cellobiohydrolase from Trichoderma reesei with Microcrystalline Cellulose Ibeta. Cellulose, 15, 261-273. http://dx.doi.org/10.1007/s10570-007-9186-0

[57] Zhang, Y.H.P. and Lynd, L.R. (2005) Determination of the number-average degree of polymerization of cellodextrins and cellulose with application to enzymatic hydrolysis. Biomacromolecules, 6, 1510-1515. http://dx.doi.org/10.1021/bm049235j

[58] Nishiyama, Y., Johnson, G.P. and French, A.D. (2012) Diffraction from nonperiodic models of cellulose crystals. Cellulose, 19, 319-336. http://dx.doi.org/10.1007/s10570-012-9652-1

[59] Hurd, A.J., Schaefer, D.W. and Glines, A.M. (1988) SANS
Study of Sinstering of Rough Surfaces. Journal of Applied Crystallography, 21, 864-869. http://dx.doi.org/10.1107/S0021889888005734

[60] Broseta, D., Barre, L., Vizika, O., Shahidzadeh, N., Guilbaud, J.P. and Lyonnard, S. (2001) Capillary condensation in a fractal porous medium. Physical Review Letters, 86, 53135316. http://dx.doi.org/10.1103/PhysRevLett.86.5313

[61] Thygesen, L.G., Hidayat, B.J., Johansen, K.S. and Felby, C. (2011) Role of supramolecular cellulose structures in enzymatic hydrolysis of plant cell walls. Journal of Industrial Microbiology \& Biotechnology, 38, 975-983. http://dx.doi.org/10.1007/s10295-010-0870-y

[62] Clarke, K., Li, X. and Li, K. (2011) The mechanism of fiber cutting during enzymatic hydrolysis of wood biomass. Biomass and Bioenger, 35, 3943-3950. 